\title{
The Solvent Effects on the Optical Rotatory Dispersion of $N$-Thioacyl Derivatives of $\alpha$-Amino Acids
}

Various types of solvent effects on the optical rotatory dispersion (ORD) and circular dichroism (CD) measurements of $\alpha$-substituted cyclohexanones, ${ }^{1,2)}$ bridged bicyclic ketones $^{3,4}$ have been reported, and they have been reviewed recently by Djerassi, et $a .^{5}{ }^{5}$ together with other cases. Very recently studies on ORD and CD curves, associated with thionamides by changing the solvents, have been presented $\left.{ }^{6}\right)$ and the conformational and/or solvational equilibria in solution have been discussed by the same group. ${ }^{7 \sim 9)}$

In the previous communication, the present authors have reported the remarkable solvent effects on the ORD and CD measurements of the dithiocarbamates of amino acids. ${ }^{10)}$ We tried to extend our findings to the other thiono derivatives of $\alpha$-amino acids in order to ascertain whether or not similar striking solvent effects would occur. In this communication, the authors wish to present the results of the solvent effects on the measurement of ORD curves of N-phenylthioacetyl-, and $\mathrm{N}$-thioacetyl- $\alpha$-amino

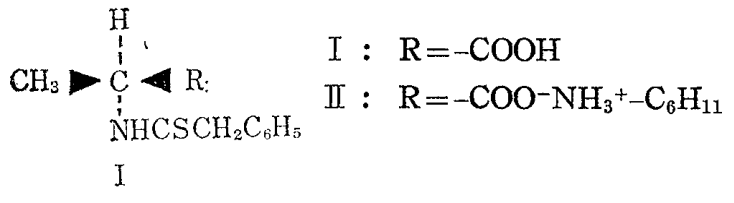

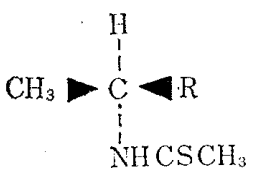<smiles>[R]C1CCCN1[Ge]CCCCCCCC</smiles>

$\mathrm{V}: \mathrm{R}=-\mathrm{COOH}$

$\mathrm{V}: \mathrm{R}=-\mathrm{COO}^{-} \mathrm{NH}_{3}{ }^{+}-\mathrm{C}_{6} \mathrm{H}_{11}$ acids in various solvents, though the ORD curves of the former had been already reported by Sjöberg, et al. ${ }^{11)}$ who indicated that cyclohexylammonium salts of $\mathrm{N}$-phenylthioacetyl-L-amino acids gave rise to a negative Cotton effect in methanol, and that $\mathrm{N}$-phenylthioacetyl-L-asparagine which was not a salt form also had a negative Cotton effect in the same solvent, and hence it was concluded that the sign of the Cotton effect was generally negative for $\mathrm{N}$-phenylthioacety1-L-amino acids, even though the same derivatives of $\mathrm{L}$-proline and $\mathrm{L}$-hydroxy proline which exhibited a positive Cotton effect was exceptional.

The authors reinvestigated their results from the standpoint of solvent effects similary to those reported previously. ${ }^{10)}$ When water was used as a

1) C. Djerassi, L. E. Geller : Tetrahedron, 3, 319 (1958); C. Djerassi, L. E. Geller, E. J. Eisenbraun : J. Org. Chem., 25, $1(1960)$; C. Djerassi, E. J. Warawa, R. E. Wolff, E. J. Eisenbraun : Ibid., 25, 917 (1960); J. Allinger, N. L. Allinger, L. E. Geller, C. Djerasssi : Ibid., 26, 3521 (1961).

2) C. Djerassi, R. Records, B. Bach : Chem. \& Ind. (London), 1961, 258.

3) H. P. Gervais, A. Rassat : Bull soc. chim. France, 1961, 743.

4) C. Coulombeau, A. Rassat: Ibid., 1963, 2673.

5) A. Moscowitz, K. M. Wellman, C. Djerassi : Proc. Nat. Acad. Sci., 50, 799 (1963).

6) J. V. Burakevich, C. Djerassi : J. Am. Chem. Soc., 87, 51 (1965).

7) K. M. Wellman, C. Djerassi : Ibid., 87, 60 (1965).

8) K. N. Wellman, P.H. A. Laur, W.S. Briggs, A. Moscowitz, C. Djerassi : Ibid., 87, 66 (1965).

9) K. M. Wellman, W.S. Briggs, C. Djerassi : Iibd., 87, 73 (1965).

10) S. Yamada, K. Ishikawa, K. Achiwa: This Bulletin, 13, 892 (1965).

11) B. Sjöberg, B. Karlén, R. Dahlbom: Acta Chem. Scand., 16, 1071 (1962). 
solvent, cyclohexylammonium salts of $\mathrm{N}$-phenylthioacetyl derivatives of $\mathrm{L}$-alanine (II), L-proline ( $\mathrm{U})$, L-asparagine (VII) and of N-thioacetyl derivative of L-alanine (N), exhibited a positive Cotton effect, respectively (Fig. 1), and the location of the Cotton effect, with the first extremum appearing near $360 \mathrm{~m} \mu$, showed quite clearly that this anomalous character of dispersion curve was responsible for the optically active $>\mathrm{C}=\mathrm{S}$ ultraviolet absorption band, therefore in this instance, $\mathrm{L}$-proline derivative was not found to be exceptional, and the fact that $N$ without phenyl group in a thiocarbonyl moiety, also exhibited a positive Cotton effect, has proved that the phenyl group of phenylthioacetyl part was indifferent to the Cotton effect.

On the other hand, when the solvent used on the measurements of the above derivatives, II, $\mathrm{N}, \mathrm{V}$, and $\mathrm{VII}$, was changed from water to methanol, the Cotton effect of $\mathbb{I}, \mathrm{N}$, and III was inversed respectively to exhibit a negative one, but the inversion of the Cotton effect of $\mathrm{V}$, being cyclic compound, was not observed (Fig. 2).

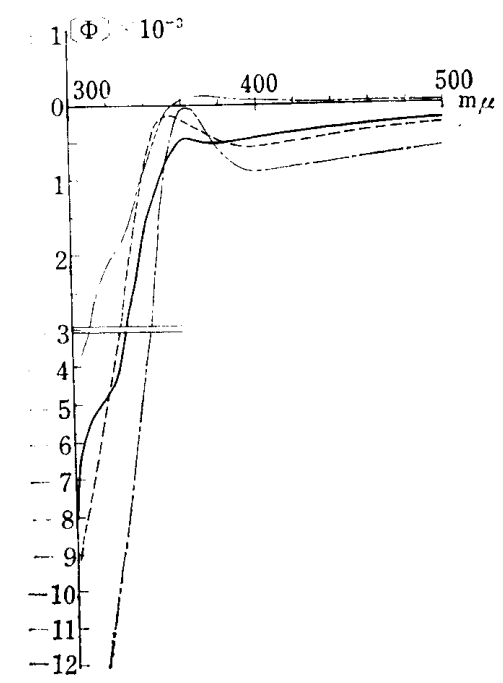

Fig. 1. Optical Rotatory Dispersion Curves of II, N, $\mathrm{I}$, UII in Water

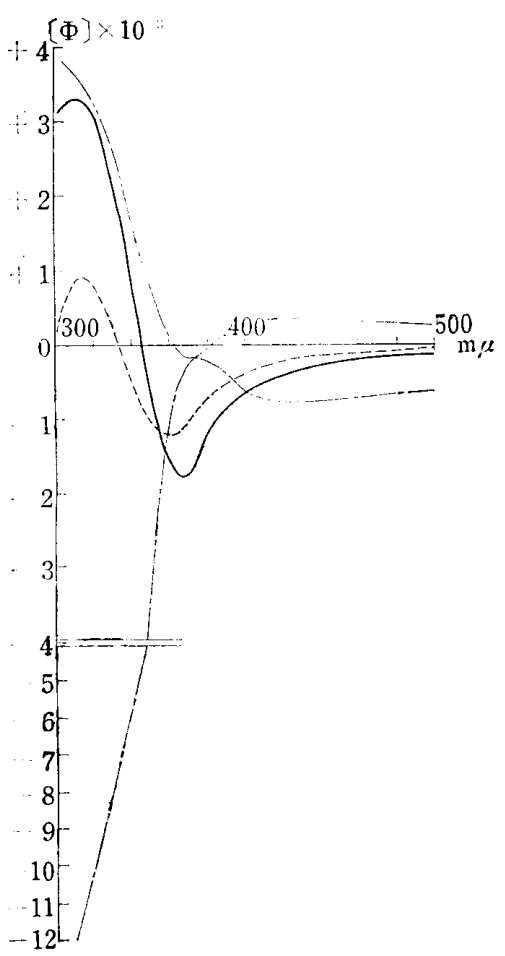

Fig. 2. Optical Rotatory Dispersion Curves of $I, N, \mathrm{H}$, UII in Methanol

$$
\text { II : }
$$

The ORD curve of N-phenylthioacetyl-L-alanine (I), -L-proline (V) and N-thioacetyl$\mathrm{L}$-alanine (III) was determined in methanol as a polar solvent and in chloroform as a nonpolar solvent. In methanol solution $\mathrm{I}$, II, and $\mathrm{V}$ exhibited a positive Cotton effect (Fig. 3) which was consistent with the generalization that dithiocarbamates of the L-amino acids showed a positive Cotton effect in methanol solution, ${ }^{10}$ ) as well as the $\mathrm{N}$-thionocarbethoxy derivative of L-amino acids, except those of L-hydroxyproline and L-acetoxyproline, ${ }^{12)}$ moreover, a sign of the Cotton effect of I in water was also positive as expected (Fig. 5). However, when the ORD curves of these compounds were examined in chloroform solution, the inversion from a positive Cotton effect to negative was taken place in the cases of $I$ and III, but no change was observed in the case

12) C. Djerassi, K. Undheim, R. C. Sheppard, W.G. Terry, B. Sjöberg : Acta Chem. Scand., 15, 903 (1961). 


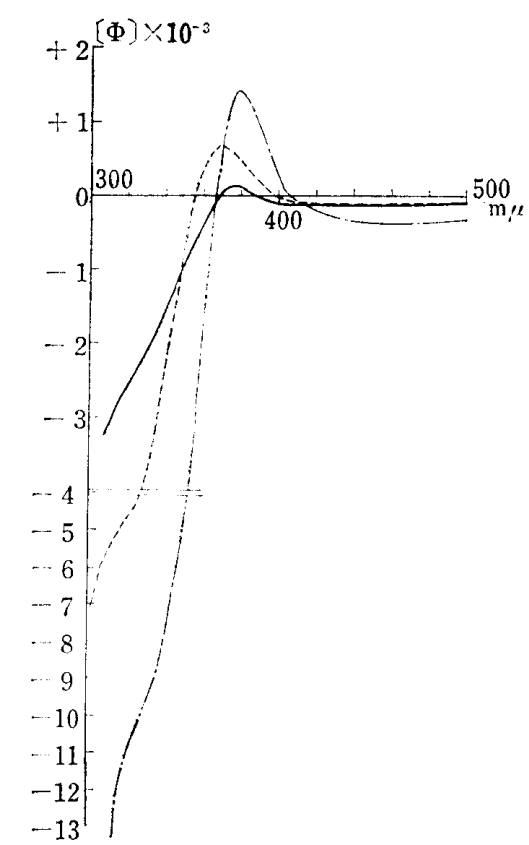

Fig. 3. Optical Rotatory Dispersion Curves of $I$, II, $\mathrm{V}$ in Methanol

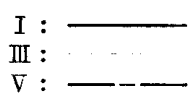

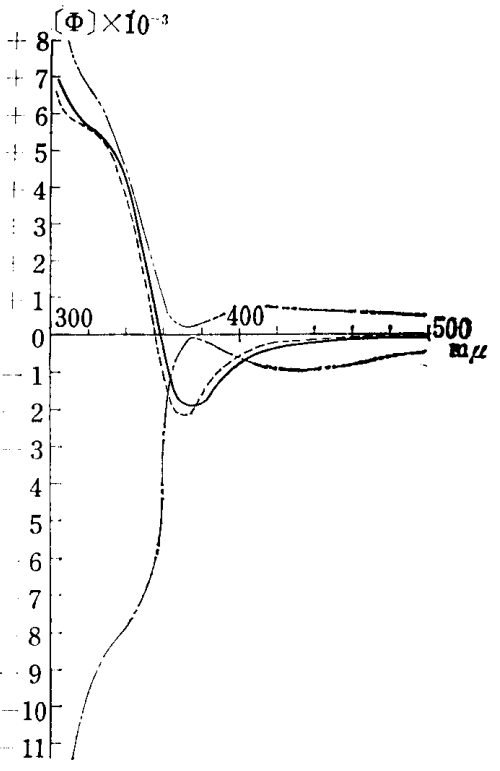

Fig. 4. Optical Rotatory Dispersion Curves of I, III, V, VI in Chloroform (1\% EtOH)

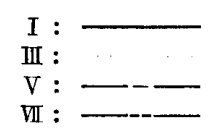

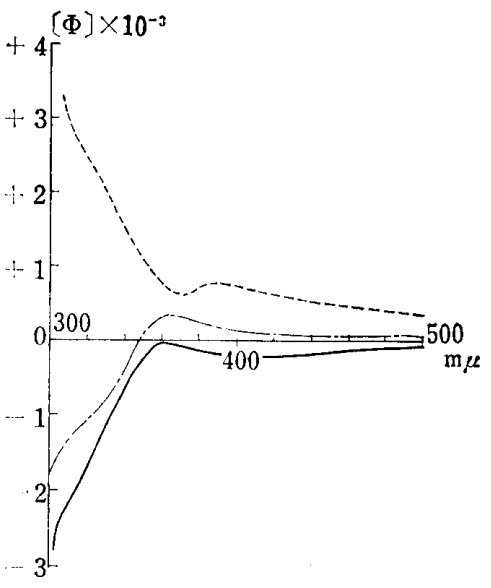

Fig. 5. Optical Rotatory Dispersion Curves of I, VII

$\mathrm{I}$ in $\mathrm{H}_{2} \mathrm{O}$ :

III in $\mathrm{CH}_{3} \mathrm{OH}$ :

VII in $\mathrm{H}_{2} \mathrm{O}$ :

of V (Fig. 4). This observation is very similar to those of dithiocarbamates of $\alpha$-amino acids. $* 1,10)$

Sjöberg, et al. also reported that the ORD curve of $\mathrm{N}$-phenylthioacetyl-L-asparagine (VI) exhibited a negative Cotton effect in methanol solution. If the phenylthioacetyl derivative of L-amino acids produces generally a positive Cotton effect in a polar solvent such as methanol (Fig. 3), a negative Cotton effect of VII in methanol solution would be exceptional, contrary to the Sjöberg's proposal. However, a change of solvent from methanol to water, more polar solvent, gave rise to the Cotton effect of VI from negative to positive, being different from the cases of I and III. In chloroform a sign of Cotton effect of VI was negative as in methanol, its amplitude being larger than the case in methanol (Figs. 4, 5).

TABLE I. Signs of Cotton Effects of Some N-Phenylthioacetyl$\boldsymbol{\alpha}$-Amino Acids and Their Salts

\begin{tabular}{|c|c|c|c|c|c|c|c|c|}
\hline \multirow{2}{*}{ Solvents } & \multicolumn{4}{|c|}{ L-Alanine derivatives } & \multicolumn{2}{|c|}{ L-Proline derivatives } & \multicolumn{2}{|c|}{$\mathrm{L}$-Asparagine derivatives } \\
\hline & $\begin{array}{l}\text { Free acid } \\
\text { (I) }\end{array}$ & $\begin{array}{l}\text { Salt } \\
\text { (II) }\end{array}$ & $\begin{array}{l}\text { Free acid } \\
\text { (III) }\end{array}$ & $\begin{array}{l}\text { Salt } \\
\text { (N) }\end{array}$ & $\begin{array}{l}\text { Free acid } \\
\text { (V) }\end{array}$ & $\begin{array}{l}\text { Salt } \\
\text { (V) }\end{array}$ & $\begin{array}{l}\text { Free acid } \\
\text { (VII) }\end{array}$ & $\begin{array}{l}\text { Salt } \\
\text { (VIII) }\end{array}$ \\
\hline $\begin{array}{l}\mathrm{H}_{2} \mathrm{O} \\
\mathrm{CH}_{3} \mathrm{OH} \\
\mathrm{CHCl}_{3}\end{array}$ & $\begin{array}{l}(+) \\
(+) \\
(-)\end{array}$ & $\begin{array}{l}(+) \\
(-)\end{array}$ & $\begin{array}{l}(+) \\
(-)\end{array}$ & $\begin{array}{l}(+) \\
(-)\end{array}$ & $\begin{array}{l}(+) \\
(+)\end{array}$ & $\begin{array}{l}(+) \\
(+)\end{array}$ & $\begin{array}{l}(+) \\
(-)^{a)} \\
(+)^{b)}\end{array}$ & $\begin{array}{l}(+) \\
(-)\end{array}$ \\
\hline
\end{tabular}

(t): Positive Cotton effect

$(-)$ : Negative Cotton effect

a) The amplitude is smaller than that in chloroform.

b) The chloroform solution contains $10 \%$ methanol because of insolubility of the substance.

*1 Cotton effect of $\mathrm{N}$-dithiocarbethoxy-L-proline has been found to be positive in every solvent, such as methanol, dioxane, and chloroform. The data are not published. 
The table I summarizes the ORD data obtained in water, methanol and chloroform with $\mathrm{N}$-phenylthioacetyl and $\mathrm{N}$-thioacetyl derivatives of $\mathrm{L}$-alanine, L-proline, and $\mathrm{L}$-asparagine.

The solvent-induced inversion in sign of the Cotton effect remains unexplained. However, it seems to be not enough to discuss the causes of these solvent effects and also to be difficult to establish a general rule on these phenomena because of the limited number of derivatives, but the following matters may be said,

1) In the case of salt forms such as II, $N$, and UII, the inversion of a sign of the Cotton effect occurs by changing the solvent from water to methanol, and in the case of free acid forms, I, II, and VI similar inversion occurs by changing the solvent from methanol to chloroform (I and III) or from water to either methanol or chloroform (VI), however no change of a sign occurs in the cases of $\mathbb{N}$ and V. It may be supposed that a sign of the ORD curves of N-thioacyl-L-amino acids and their salts changes from positive to negative by changing the solvent from "polar" to "nonpolar" except V and $V$. Hence this inversion appears to be associated with the participation of the rotation of bonding between asymmetric carbon atom and nitrogen atom.

2) The contradiction proposed by Sjöberg, et al. ${ }^{11}$ has been resolved and proline derivative was found not to be exceptional, but asparagine derivative would be rather anomalous because of the probable participation of neighboring amide group. The solvent effects on $\mathrm{N}$-thioacyl and $\mathrm{N}$-dithiocarbethoxy derivatives of amino acids are alike since thione group seems to play an important role, although the transition states of $>\mathrm{N}-\mathrm{C}=\mathrm{S}$ and $>\mathrm{N}-\mathrm{C}-\mathrm{S}-$ might be a little different.<smiles>CCCCCCCC</smiles>

We are now continuing on the studies pursuing the causes of these phenomena and our findings will be extended to various types of thiono amino acids and amines.

Faculty of Pharmaceutical Sciences, University of Tokyo,

Bunkyo-ku, Tokyo, Japan
Shun-ichi Yamada (山田俊一)

Kiyoyasu Ishikawa (石川清康)

Kazuo Achiwa (阿知波一雄)

Received July 12, 1965 